\title{
Experiment Modeling of Response Parameters and CBN Tool Wear in Continuous and Interrupted Hard Turning of AISI D6 Steel
}

\author{
Manoj Nayak ${ }^{1 *}$ and Rakesh Sehgal ${ }^{2}$ \\ 'Department of Mechanical Engineering, Manav Rachna International Institute of Research and Studies, \\ Sector 43, Faridabad - 121004, Haryana, India; \\ manojnayak69@gmail.com \\ 2Department of Mechanical Engineering, National Institute of Technology, Hazratbal - 190006, Srinagar, \\ Jammu and Kashmir, India; \\ rakesh_sehgal@rediffmail.com
}

\begin{abstract}
Objectives: This study aims at providing solution to shop floor engineers on parametric selection of hard machining during reconditioning of damaged tools and dies after a certain period of life. Methods/Statistical Analysis: Experiments were conducted for hard turning of continuous and interrupted surfaces using Cubic Boron Nitride (CBN) tools on a highly automated all geared lathe using force dynamometer and surface roughness tester. In this experiment the influence of cutting speed, feed and CBN tool material properties on main cutting force, thrust force, surface roughness and cutting temperature has been experimentally investigated in continuous and interrupted turning. A total of 54 experiments were conducted for both continuous and interrupted surfaces and standard statistical methodology is applied. Findings: Statistical checks (ANOVA analysis, R2 statistics, p-values) indicated that the models were adequate. Thrust force is higher and surface finish is better in case of interrupted cutting as compared to continuous cutting. The results also showed that the feed strongly influences the main cutting force and surface roughness; cutting speed strongly influences the cutting temperatures; feed strongly influence the surface roughness in both continuous and interrupted machining. The predicted responses were close to the experimental values and the proposed experimental models can be used to improve the hard turning processes. Chipping of the cutting edge was predominantly found in continuous turning but did not occur in interrupted turning at $102 \mathrm{~m} / \mathrm{min}$. The tools failed mechanically at very low speed in both the cases. Abrasion, adhesion, diffusion and chemical wear are the different wear mechanisms observed during hard turning of AISI D6 steel. Application/Improvements: This research establishes the capability of hard turning as an alternative to grinding process so as to avoid use of cutting fluid due environmental hazards. By selecting proper process parameters of speed, feed and depth of cut, selection of tool grade, dry hard turning can be accomplished economically.
\end{abstract}

Keywords: Continuous, Cutting Force, Hard Turning, Interrupted, Surface Roughness

\section{Introduction}

Precision finish hard turning has the potential to replace the grinding operation in some applications. In some cases components are hard turned to remove the distortions due to hardening and tempering, to achieve a better

${ }^{*}$ Author for correspondence 
surface finish. But in some applications, the component's surfaces interrupted by holes, keyways, flow channels for lubrication, splines etc are found to be difficult for machining because tool life is unstable due to sudden breakage of cutting edge. Hence conventional grinding still remains the main process in such applications. But with the advent of CBN tools technology, these processes, were successfully carried out in industries, thereby resulting in less grinding operations, low cutting fluid consumption, lead time reduction in manufacturing, flexibility in the process planning, good surface finish and higher material removal rates according to ${ }^{1}$. But to boost the productivity and to bring down the cost of finishing, a proper assessment of machinability of engineering material and cutting capability of tools are required. Research on assessing machinability of work material, monitoring tool wear and tool lives, evaluating surface integrity, experimental modeling and analysis are done to give a new direction to metal cutting research.

Moreover, the cutting force data are essential while selecting work material, cutting tool material, machine tools and their power consumption. Surface roughness plays an important role in the functionality of the machined components. Cutting temperatures can provide critical information on thermal aspect of the machined surface characteristics and heat diffussion within the tool probably brings in variation in mechanical characteristics of the tool material. Since CBN tools are used for hard finishing and the cutting regime employed may generate high forces, which may cause chatter and vibration and damage the machining quality.

Therefore, understanding the changing patterns of surface roughness, cutting forces and cutting temperature becomes an important study. In investigated the machinabilty of AISI 52100 steel based on cutting forces, temperatures and residual stresses using coated carbides, ceramics and CBN tools and found that the cutting force increases with workpiece hardness, nose radius, feed and negative rake angle.

Mechanistic force modeling of hard turning were presented by $\underline{2}$ using sharp and worn CBN tools and they found that the total force are the linear summation of each cutting forces due to chip formation and force due to flank wear of tools. The model was then calibrated and validated by the machining data of AISI 52100 using CBN tools. $\mathrm{In}^{3}$ presented a hybrid thermo- mechanical model during investigation of AISI H13 steel taking into consideration the effect of strain-rate, workpiece hardness and cutting temperatures. The simulation results showed the feed force to be dominant than the main cutting force and with increase in feed rate and nose radius the main cutting force increased according. A cutting force model was also proposed by ${ }^{4}$ considering the thermal properties of both low and high content CBN tools during hard machining of AISI H13 steel. Their model predicted lower main cutting force, thrust force and high chip-tool temperature using low $\mathrm{CBN}$ content tools. $\mathrm{In}^{\underline{5}}$ found that the honed tools resulted in lower main cutting force and higher temperature on the tool rake face. $\operatorname{In}^{6}$ found that the cutting forces were higher during maching of steel with low hardness. $\operatorname{In}^{7}$ represented a power function type equation to correlate cutting forces and cutting parameters. $\mathrm{In}^{\underline{8}}$ concluded that the surface finish increases with increase cutting speed and the thrust force to be dominant among the three forces during too hard turning.

Recently, demand for lower machining cost has grown in heavy interrupted cutting and CBN meets the challenge because of its high hardness and thermal conductivity next to diamond and shows low reactivity with ferrous materials. Although $\mathrm{CBN}-\mathrm{H}$ tools are better candidate for such interrupted turning, the limitation is that the tool wear accelerates at high speed owing to their greater affinity to steel workpiece because of the metallic binder. $\mathrm{In}^{2}$ in their experimental studies suggest that the CBN-L tools are exceptional in terms of surface quality and tool wear as compared to $\mathrm{CBN}-\mathrm{H}$ tools. $\mathrm{In}^{10}$ found that CBN-L constantly accomplished superior results compared to $\mathrm{CBN}-\mathrm{H}$ in intermittent machining of PM M50 hardened steel. $\mathrm{In}^{11}$ found the CBN-L to be exceptionally good than $\mathrm{CBN}-\mathrm{H}$ in terms of tool life at moderate speed. In observed excellent wear resistance during interrupted hard turning using CBN-L tools, owing to the fine CBN grains, which provide the tool with high hardness and high transverse, rupture strength. $\operatorname{In}^{12}$ found that the 
CBN-L is the most suitable tool in interrupted cutting irrespective of any kind of cutting edge micro-geometry. In ${ }^{13,14}$ studied the effect of CBN tool grades and its geometry on machinability of AISI D6 tool steel and suggested the parametric solution of use of CBN-L tool grades.

As can be seen from the literatures, cutting performances of $\mathrm{CBN}-\mathrm{H}, \mathrm{CBN}-\mathrm{L}$ and ceramics tool materials has been widely accepted in hard machining field in industries but the CBN-L tools give better performance in interrupted hard turning in terms of tool lives and surface roughness.

Undoubtedly, in order to prevent excessive tool wear and tool breakage due to the inherenent characteristics of hardness and interruptions of those specific industrial hard components mentioned and in order to assess maximum gain and economic viability by the manufacturer for utilizing interrupted and continuous hard turning process, the prediction models are constructed to get an insight of the process. In the current work, the focus is on the comparative study of the influence of cutting speed, feed and CBN-L grades, which affect the machinability characteristics like main cutting force $\left(\mathrm{F}_{\mathrm{c}}\right)$; thrust force $\left(\mathrm{F}_{\mathrm{p}}\right)$; cutting temperatures $(\mathrm{T})$ and surface roughness $\left(\mathrm{R}_{\mathrm{a}}\right)$ during hard turning of AISI D6 steel with continuous and interrupted surfaces. The analysis of the tool wear using Scanning Electron Microscope (SEM) has also been carried out to affirm the tool wear and tool wear mechanisms.

\section{Experiment Details}

Longitudinal turning tests (short duration of machining length of $20 \mathrm{~mm}$ ) were performed in an all geared DRO lathe (Model: Bajaj-Pioneer-175 geared headed) having eight spindle speeds (8-2400 rpm) and 24 number of feeds.
A dynamometer with three axes tool-post piezoelectric sensors (make TeLC Germany) was used to measure the cutting forces. Temperatures were measured using a radiation sensor (InGaAs, 24VDC, 4-20 mA; measuring range $300-800^{\circ} \mathrm{C}$ ) based on infrared principle capable of measuring the temperature of a smallest spot (less than 2 $\mathrm{mm}$ ) near the tool tip. Since emissivity plays a significant role in such devices during measuring of temperature, as it changes with the change in temperature during machining of the workpiece, these devices are just sufficient for measuring the temperature for a comparative study. So, taking this into consideration, the infrared pyrometer, considers the default value of the emissivity and do not generate the absolute values of the temperatures data. Necessary care was taken, to maintain a similar condition during measurement of temperatures. XKM software was used in the dynamometer to measure cutting forces and cutting temperature. Surface roughness was measured offline with the help of surface roughness tester (SJ-301 Mitotoyo, Japan) by taking the measurement across the lay. The average $R_{a}$ value of three measurements $\left(\lambda_{c}=0.8\right.$ $\mathrm{mm} ; \mathrm{N}=5 \mathrm{~mm}$ ) across the feed length about $120^{\circ}$ apart was used for analysis. Machining of AISI D6 (54 \pm 2 HRC) with material composition as given in Table 1 was machined under dry condition with a constant depth of cut of $0.15 \mathrm{~mm}$ using the three different grades of CBN tools with different mechanical and thermal properties as laid down in Table 2. Work-piece for interrupted surfaces were prepared by milling six slots of $8 \mathrm{~mm} \times 6 \mathrm{~mm}$ on cylindrical surfaces for interrupt machining and plain cylindrical surface work-piece were used for continuous machining. A total of 54 experiments i.e. a full factorial design $\left(\mathrm{L}_{27}\right)$ each for two types of surfaces continuous and interrupted workpiece as shown in Figure 1 were con-

Table 1. Chemical composition of AISI D6 tool steel

\begin{tabular}{|c|c|c|c|c|c|c|c|}
\hline Elements & $\mathbf{C}$ & Si & Mn & Cr & Mo & Co & W \\
\hline \% Weights & 2.13 & 0.238 & 0.24 & 11.10 & 0.032 & 0.020 & 0.620 \\
\hline
\end{tabular}


Table 2. Thermo-mechanical properties of tool materials ${ }^{21}$

\begin{tabular}{|c|c|c|c|}
\hline Tool type/ Properties & CBN-1 & CBN-2 & CBN-3 \\
\hline Binder & TiC & TiN & TiN \\
\hline Grain Size $(\mu \mathrm{m})$ & $0.5-1$ & 3 & 3 \\
\hline CBN \% & 45 & $40-45$ & $55-60$ \\
\hline $\begin{array}{c}\text { Base Material hardnes } \\
(\mathrm{HV})\end{array}$ & 2500 & $2800-3000$ & $3200-3400$ \\
\hline $\begin{array}{c}\text { Transverse Rupture } \\
\text { Strength (Gpa) }\end{array}$ & 1250 & $800-900$ & $1000-1100$ \\
\hline $\begin{array}{c}\text { Thermal Conductivity } \\
\text { (Watt/mK) }\end{array}$ & 44 & -- & 54 \\
\hline
\end{tabular}

Table 3. Factors along with their coded variables

\begin{tabular}{|c|c|c|c|}
\hline Levels & $\mathbf{- 1}$ & $\mathbf{0}$ & $\mathbf{+ 1}$ \\
\hline $\begin{array}{c}\text { Cutting Speed } \\
(\mathrm{A}) \mathrm{m} / \mathrm{min}\end{array}$ & 54.03 & 93.62 & 132.92 \\
\hline Feed (B) mm/rev & 0.08 & 0.133 & 0.210 \\
\hline CBN Grades (C) & CBN-1 & CBN-2 & CBN-3 \\
\hline $\begin{array}{c}\text { Workpiece } \\
\text { Geometry }\end{array}$ & Continuous & - & Interrupted \\
\hline
\end{tabular}
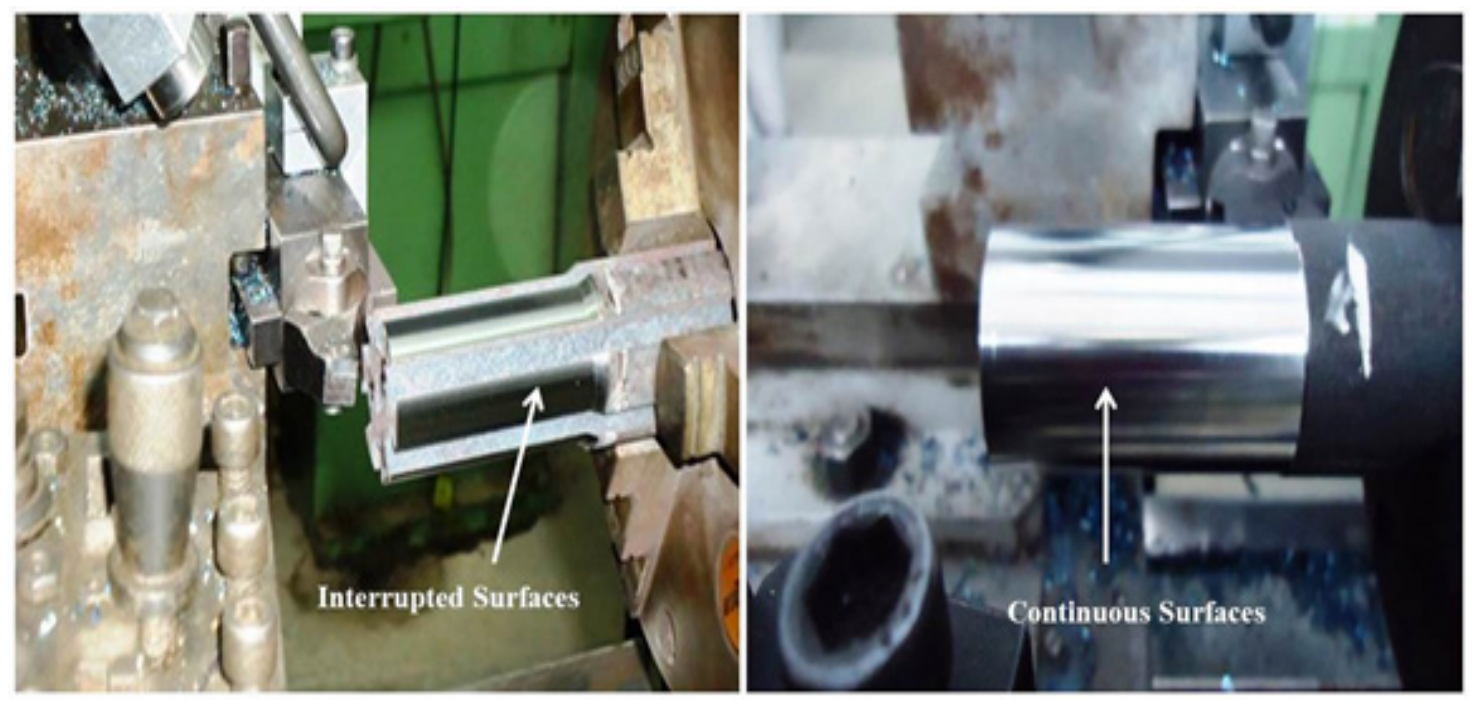

Figure 1. Machining set-up with interrupted and continuous surfaces. 
Table 4. Statistical report of the experimental data's along with the predicted value

\begin{tabular}{|c|c|c|c|c|c|c|c|c|c|c|c|}
\hline \multirow{3}{*}{$\begin{array}{l}\text { Std. } \\
\text { Ord. }\end{array}$} & \multirow{3}{*}{$\begin{array}{l}\text { CBN } \\
\text { type }\end{array}$} & \multirow{3}{*}{$\begin{array}{l}\text { Cutg. } \\
\text { speed } \\
\text { m/min }\end{array}$} & \multirow{3}{*}{$\begin{array}{c}\text { Feed in } \\
\mathrm{mm} / \\
\text { rev. }\end{array}$} & \multicolumn{4}{|c|}{ Main Cutting Forces } & \multicolumn{4}{|c|}{ Thrust Forces } \\
\hline & & & & \multicolumn{2}{|c|}{ Continuous } & \multicolumn{2}{|c|}{ Interrupted } & \multicolumn{2}{|c|}{ Continuous } & \multicolumn{2}{|c|}{ Interrupted } \\
\hline & & & & Exp. & Pred. & Exp. & Pred. & Exp. & Pred. & Exp. & Pred. \\
\hline 1 & $\begin{array}{c}\text { CBN- } \\
1\end{array}$ & 54.03 & 0.080 & 67 & 62.51 & 68 & 68.29 & 184 & 183.75 & 213 & 201.29 \\
\hline 2 & $\begin{array}{c}\text { CBN- } \\
1\end{array}$ & 93.62 & 0.080 & 68 & 65.95 & 72 & 68.29 & 201 & 208.09 & 200 & 210.96 \\
\hline 3 & $\begin{array}{c}\text { CBN- } \\
1\end{array}$ & 132.92 & 0.080 & 45 & 54.62 & 66 & 68.29 & 172 & 179.53 & 217 & 220.63 \\
\hline 4 & $\begin{array}{c}\text { CBN- } \\
1 \\
\end{array}$ & 54.03 & 0.133 & 72 & 74.07 & 55 & 59.64 & 187 & 185.88 & 113 & 135.70 \\
\hline 5 & $\begin{array}{c}\text { CBN- } \\
1 \\
\end{array}$ & 93.62 & 0.133 & 86 & 77.51 & 60 & 59.64 & 223 & 210.21 & 158 & 145.37 \\
\hline 6 & $\begin{array}{c}\text { CBN- } \\
1\end{array}$ & 132.92 & 0.133 & 67 & 66.18 & 62 & 59.64 & 192 & 181.65 & 170 & 155.05 \\
\hline 7 & $\begin{array}{c}\text { CBN- } \\
1 \\
\end{array}$ & 54.03 & 0.210 & 88 & 90.87 & 96 & 91.09 & 148 & 149.59 & 237 & 223.32 \\
\hline 8 & $\begin{array}{c}\text { CBN- } \\
1\end{array}$ & 93.62 & 0.210 & 93 & 94.31 & 85 & 91.09 & 183 & 173.93 & 217 & 233.00 \\
\hline 9 & $\begin{array}{c}\text { CBN- } \\
1\end{array}$ & 132.92 & 0.210 & 83 & 82.98 & 93 & 91.09 & 128 & 145.37 & 243 & 242.67 \\
\hline 10 & $\begin{array}{c}\text { CBN- } \\
2 \\
\end{array}$ & 54.03 & 0.080 & 64 & 63.95 & 58 & 64.67 & 158 & 149.51 & 215 & 242.38 \\
\hline 11 & $\begin{array}{c}\text { CBN- } \\
2\end{array}$ & 93.62 & 0.080 & 62 & 67.40 & 72 & 64.67 & 178 & 173.84 & 261 & 252.05 \\
\hline 12 & $\begin{array}{c}\text { CBN- } \\
2\end{array}$ & 132.92 & 0.080 & 57 & 56.06 & 68 & 64.67 & 160 & 145.29 & 295 & 261.72 \\
\hline 13 & $\begin{array}{c}\text { CBN- } \\
2\end{array}$ & 54.03 & 0.133 & 75 & 75.51 & 58 & 54.92 & 156 & 172.70 & 178 & 174.69 \\
\hline 14 & $\begin{array}{c}\text { CBN- } \\
2\end{array}$ & 93.62 & 0.133 & 79 & 78.96 & 48 & 54.92 & 178 & 197.03 & 152 & 184.36 \\
\hline 15 & $\begin{array}{c}\text { CBN- } \\
2 \\
\end{array}$ & 132.92 & 0.133 & 66 & 67.63 & 52 & 54.92 & 158 & 168.47 & 198 & 194.03 \\
\hline 16 & $\begin{array}{c}\text { CBN- } \\
2 \\
\end{array}$ & 54.03 & 0.210 & 92 & 92.31 & 91 & 84.75 & 177 & 167.02 & 287 & 259.25 \\
\hline 17 & $\begin{array}{c}\text { CBN- } \\
2\end{array}$ & 93.62 & 0.210 & 99 & 95.76 & 87 & 84.75 & 198 & 191.35 & 280 & 268.93 \\
\hline 18 & $\begin{array}{c}\text { CBN- } \\
2\end{array}$ & 132.92 & 0.210 & 88 & 84.42 & 79 & 84.75 & 165 & 162.80 & 250 & 278.60 \\
\hline
\end{tabular}




\begin{tabular}{|c|c|c|c|c|c|c|c|c|c|c|c|}
\hline 19 & $\begin{array}{c}\mathrm{CBN}- \\
3\end{array}$ & 54.03 & 0.080 & 62 & 69.29 & 94 & 88.05 & 165 & 180.29 & 322 & 303.98 \\
\hline 20 & $\begin{array}{c}\text { CBN- } \\
3\end{array}$ & 93.62 & 0.080 & 71 & 72.73 & 82 & 88.05 & 195 & 204.62 & 299 & 313.65 \\
\hline 21 & $\begin{array}{c}\mathrm{CBN}- \\
3\end{array}$ & 132.92 & 0.080 & 69 & 61.40 & 83 & 88.05 & 188 & 176.07 & 308 & 323.33 \\
\hline 22 & $\begin{array}{c}\text { CBN- } \\
3\end{array}$ & 54.03 & 0.133 & 90 & 80.85 & 78 & 70.44 & 215 & 202.32 & 226 & 205.93 \\
\hline 23 & $\begin{array}{c}\text { CBN- } \\
3\end{array}$ & 93.62 & 0.133 & 82 & 84.29 & 77 & 70.44 & 244 & 226.65 & 221 & 215.60 \\
\hline 24 & $\begin{array}{c}\text { CBN- } \\
3\end{array}$ & 132.92 & 0.133 & 76 & 72.96 & 65 & 70.44 & 190 & 198.09 & 220 & 225.27 \\
\hline 25 & $\begin{array}{c}\mathrm{CBN}- \\
3 \\
\end{array}$ & 54.03 & 0.210 & 97 & 97.64 & 81 & 88.85 & 196 & 194.94 & 224 & 246.39 \\
\hline 26 & $\begin{array}{c}\text { CBN- } \\
3 \\
\end{array}$ & 93.62 & 0.210 & 98 & 101.1 & 93 & 88.85 & 205 & 219.28 & 248 & 256.06 \\
\hline 27 & $\begin{array}{c}\mathrm{CBN}- \\
3\end{array}$ & 132.92 & 0.210 & 85 & 89.76 & 89 & 88.85 & 195 & 190.72 & 288 & 265.79 \\
\hline
\end{tabular}

Contd..

\begin{tabular}{|c|c|c|c|c|c|c|c|c|c|c|c|}
\hline \multirow{3}{*}{$\begin{array}{l}\text { Std. } \\
\text { Ord. }\end{array}$} & \multirow{3}{*}{$\begin{array}{l}\text { CBN } \\
\text { type }\end{array}$} & \multirow{3}{*}{$\begin{array}{l}\text { Cutg. } \\
\text { speed } \\
\mathrm{m} / \mathrm{min}\end{array}$} & \multirow{3}{*}{$\begin{array}{c}\text { Feed in } \\
\mathrm{mm} / \\
\mathrm{rev} .\end{array}$} & \multicolumn{4}{|c|}{ Cutting Temperatures } & \multicolumn{4}{|c|}{ Surface Roughness } \\
\hline & & & & \multicolumn{2}{|c|}{ Continuous } & \multicolumn{2}{|c|}{ Interrupted } & \multicolumn{2}{|c|}{ Continuous } & \multicolumn{2}{|c|}{ Interrupted } \\
\hline & & & & Exp. & Pred. & Exp. & Pred. & Exp. & Pred. & Exp. & Pred. \\
\hline 1 & $\begin{array}{c}\text { CBN- } \\
1\end{array}$ & 54.03 & 0.080 & 482 & 480.94 & 402 & 402.53 & 0.47 & 0.53 & 0.44 & 0.61 \\
\hline 2 & $\begin{array}{c}\text { CBN- } \\
1\end{array}$ & 93.62 & 0.080 & 551 & 538.11 & 425 & 430.77 & 0.79 & 0.64 & 0.53 & 0.61 \\
\hline 3 & $\begin{array}{c}\text { CBN- } \\
1\end{array}$ & 132.92 & 0.080 & 511 & 504.61 & 448 & 438.63 & 0.56 & 0.59 & 0.52 & 0.61 \\
\hline 4 & $\begin{array}{c}\text { CBN- } \\
1\end{array}$ & 54.03 & 0.133 & 484 & 491.06 & 408 & 412.10 & 0.71 & 0.74 & 0.62 & 0.51 \\
\hline 5 & $\begin{array}{c}\text { CBN- } \\
1\end{array}$ & 93.62 & 0.133 & 549 & 548.22 & 448 & 440.35 & 0.81 & 0.85 & 0.67 & 0.51 \\
\hline 6 & $\begin{array}{c}\text { CBN- } \\
1\end{array}$ & 132.92 & 0.133 & 515 & 514.72 & 448 & 448.21 & 0.77 & 0.80 & 0.84 & 0.51 \\
\hline 7 & $\begin{array}{c}\text { CBN- } \\
1\end{array}$ & 54.03 & 0.210 & 479 & 478.83 & 439 & 426.02 & 1.75 & 1.73 & 1.52 & 1.59 \\
\hline
\end{tabular}




\begin{tabular}{|c|c|c|c|c|c|c|c|c|c|c|c|}
\hline 8 & $\begin{array}{c}\text { CBN- } \\
1\end{array}$ & 93.62 & 0.210 & 534 & 536.00 & 443 & 454.27 & 1.83 & 1.84 & 1.58 & 1.59 \\
\hline 9 & $\begin{array}{c}\text { CBN- } \\
1\end{array}$ & 132.92 & 0.210 & 490 & 502.50 & 454 & 462.12 & 1.81 & 1.78 & 1.43 & 1.59 \\
\hline 10 & $\begin{array}{c}\text { CBN- } \\
2\end{array}$ & 54.03 & 0.080 & 458 & 473.11 & 380 & 379.97 & 0.58 & 0.54 & 0.93 & 0.77 \\
\hline 11 & $\begin{array}{c}\text { CBN- } \\
2\end{array}$ & 93.62 & 0.080 & 537 & 536.11 & 422 & 408.22 & 0.53 & 0.64 & 0.56 & 0.77 \\
\hline 12 & $\begin{array}{c}\text { CBN- } \\
2\end{array}$ & 132.92 & 0.080 & 515 & 508.44 & 413 & 416.07 & 0.48 & 0.59 & 0.68 & 0.77 \\
\hline 13 & $\begin{array}{c}\text { CBN- } \\
2\end{array}$ & 54.03 & 0.133 & 483 & 483.22 & 372 & 389.55 & 0.83 & 0.72 & 0.77 & 0.77 \\
\hline 14 & $\begin{array}{c}\text { CBN- } \\
2\end{array}$ & 93.62 & 0.133 & 554 & 546.22 & 402 & 417.79 & 0.93 & 0.83 & 0.80 & 0.77 \\
\hline 15 & $\begin{array}{c}\text { CBN- } \\
2\end{array}$ & 132.92 & 0.133 & 509 & 518.56 & 411 & 425.65 & 0.89 & 0.78 & 0.99 & 0.77 \\
\hline 16 & $\begin{array}{c}\text { CBN- } \\
2\end{array}$ & 54.03 & 0.210 & 481 & 471.00 & 411 & 403.46 & 1.65 & 1.68 & 2.12 & 2.00 \\
\hline 17 & $\begin{array}{c}\text { CBN- } \\
2\end{array}$ & 93.62 & 0.210 & 536 & 534.00 & 446 & 431.71 & 1.77 & 1.79 & 2.06 & 2.00 \\
\hline 18 & $\begin{array}{c}\text { CBN- } \\
2\end{array}$ & 132.92 & 0.210 & 504 & 506.33 & 455 & 439.57 & 1.66 & 1.74 & 1.73 & 2.00 \\
\hline 19 & $\begin{array}{c}\text { CBN- } \\
3\end{array}$ & 54.03 & 0.080 & 429 & 450.28 & 386 & 396.08 & 0.54 & 0.45 & 1.98 & 1.56 \\
\hline 20 & $\begin{array}{c}\text { CBN- } \\
3\end{array}$ & 93.62 & 0.080 & 530 & 525.78 & 421 & 424.33 & 0.57 & 0.56 & 1.95 & 1.56 \\
\hline 21 & $\begin{array}{c}\text { CBN- } \\
3\end{array}$ & 132.92 & 0.080 & 515 & 510.61 & 446 & 432.19 & 0.54 & 0.51 & 1.23 & 1.56 \\
\hline 22 & $\begin{array}{c}\text { CBN- } \\
3\end{array}$ & 54.03 & 0.133 & 478 & 460.39 & 417 & 405.66 & 0.92 & 0.91 & 0.79 & 1.07 \\
\hline 23 & $\begin{array}{c}\text { CBN- } \\
3\end{array}$ & 93.62 & 0.133 & 535 & 535.89 & 443 & 433.91 & 0.92 & 1.02 & 0.76 & 1.07 \\
\hline 24 & $\begin{array}{c}\text { CBN- } \\
3\end{array}$ & 132.92 & 0.133 & 512 & 520.72 & 442 & 441.77 & 0.84 & 0.97 & 0.82 & 1.07 \\
\hline 25 & $\begin{array}{c}\text { CBN- } \\
3\end{array}$ & 54.03 & 0.210 & 463 & 448.17 & 420 & 419.58 & 2.14 & 2.27 & 1.71 & 1.57 \\
\hline 26 & $\begin{array}{c}\text { CBN- } \\
3\end{array}$ & 93.62 & 0.210 & 498 & 523.67 & 439 & 447.82 & 2.39 & 2.38 & 1.66 & 1.57 \\
\hline 27 & $\begin{array}{c}\text { CBN- } \\
3\end{array}$ & 132.92 & 0.210 & 524 & 508.50 & 443 & 455.67 & 2.53 & 2.53 & 1.69 & 1.57 \\
\hline
\end{tabular}


ducted. The level and the various parameters are defined in Table 3 with the tool material being made categorical to determine the effect of cutting speed, feeds and CBN grades at low (-1), medium (0) and high level $(+1)$ on the response variables $F_{C}, F_{P}, T$ and $R_{a}$. Randomization was strictly maintained as per the run order suggested by the DOE and 14 experiments were repeated to minimize the possible experiments error.

The inserts used were low-CBN content inserts brazed onto a tungsten carbide substrate with nose radius of 0.8 $\mathrm{mm}$ and with specific edge geometry. Each test was realized with fresh cutting edge and the cutting speeds were equalized at different workpiece diameters to the extent the rotational speeds permits. Experimental values and prediction values are as shown in Table 4 .

\section{Results and Discussions}

After performing the statistically designed experiments, the results are summarized using DOE with Design Expert Software (Version 7) and 2FI polynomial design model were used for design and regression. Standard statistical methodology is applied on the results for investigation. Then ANOVA is performed to summarize the test of the adequacy of the regression model for judging the goodness of the model. A mathematical correlation is established between the independent variables and the output characteristics. Finally, a case statistics report of analysis of residuals is generated and inspection of various diagnostic plots is done to statistically validate the model. In these regression models hierarchy principle is followed. Many statistical model builders follow hierarchy principle according to $\frac{15}{}$. In these equations the level of parameters are low (-1), medium (0) and high (+1). The term $\mathrm{AC}$ and $\mathrm{BC}$ are the linear interactions of the cutting speed and feed factor with the $\mathrm{CBN}$ tool type respectively. The variables $\mathrm{C}(1), \mathrm{C}(2), \mathrm{BC}(1), \mathrm{BC}(2), \mathrm{AC}(1)$ and $\mathrm{AC}(2)$ are coded indicator variables that are defined as follows:

Based on these models, predicted values of each response with respect to cutting conditions are given in Table 5. The error percentage of the residuals is determined (i.e difference of experimental and predicted values). The proposed models of response parameters gave a fairly reasonable result under $\pm 10 \%$ error, except the surface roughness model predicted result under \pm 20 $\%$ error because the cutting experiment involves many sources of uncertainty. Results obtained were fairly reasonable except few unacceptable results along with higher percentage of error indicating the models could explain the effects rationally considering the conclusions as drawn from a single run of experiment. $\operatorname{In}^{\frac{16}{6}}$ proposed prediction models for main cutting force and thrust force with less than $12 \%$ error and the temperature model with around $10 \%$ error during hard turning of $51 \mathrm{CrV} 4$ (58HRC) by $\mathrm{CBN}$ tools. Table 4 it can be observed that the respective minimum and maximum main cutting forces measured

Table 5. Coded indicators of the models (Montogomery, 2005)

\begin{tabular}{|c|c|c|c|}
\hline \multirow{2}{*}{ Model terms } & \multicolumn{3}{|c|}{ CBN Grades } \\
\cline { 2 - 4 } & CBN-1 & CBN-2 & CBN-3 \\
\hline$[1]$ & 1 & 0 & -1 \\
\hline $\mathrm{C}[2]$ & 0 & 1 & -1 \\
\hline $\mathrm{BC}[1]$ & 1 & 0 & -1 \\
\hline $\mathrm{BC}[2]$ & 0 & 1 & -1 \\
\hline $\mathrm{AC}[1]$ & 1 & 0 & -1 \\
\hline $\mathrm{AC}[2]$ & 0 & 1 & -1 \\
\hline
\end{tabular}


were $45 \mathrm{~N} ; 98 \mathrm{~N}$ and $48 \mathrm{~N} ; 94 \mathrm{~N}$ in continuous and interrupted turning respectively, which are very close and it did not vary much by the experimental cutting speed of $54.03 \mathrm{~m} / \mathrm{min}$ and $93.62 \mathrm{~m} / \mathrm{min}$ but the main cutting force decreased at $132.92 \mathrm{~m} / \mathrm{min}$.

This is in agreement with the investigation done by ${ }^{17}$ during hard turning. Similar observation were made for thrust forces except that the measured thrust forces during interrupted turning were of larger magnitude compared to that of the continuous turning. The cutting temperature measured in interrupted turning was lower compared to continuous turning. The surface roughness in both cases showed similar trend i.e. increased with feed rate but the surface finish generated on interrupted surface were better.

\subsection{Main Cutting Force}

The prediction equations for main cutting forces in coded variables along with the R-squared statistics are as follows:

$$
\begin{aligned}
& \mathrm{F}_{\mathrm{C}-\mathrm{CONT}}=+82.47-3.94 \mathrm{~A}+14.18 \mathrm{~B}-2.74 \mathrm{C}(1)-1.30 \mathrm{C}(2)- \\
& 7.39 \mathrm{~A}^{2} \\
& \left(\mathrm{R}^{2}=0.8991 ; \text { Adjusted } \mathrm{R}^{2}=0.8750 ; \text { Predicted } \mathrm{R}^{2}=\right. \\
& 0.8342) \\
& \mathrm{F}_{\text {C-INTER }}=+62.38+7.28 \mathrm{~B}-1.27 \mathrm{C}(1)-6.24 \mathrm{C} \quad(2)+4.11 \mathrm{BC} \\
& (1)+2.72 \mathrm{BC}(2)+18.57 \mathrm{~B}^{2} \\
& \left(\mathrm{R}^{2}=0.8723 ; \text { Adjusted } \mathrm{R}^{2}=0.8340 ; \text { Predicted } \mathrm{R}^{2}=\right.
\end{aligned}
$$
$0.7640)$

The cutting forces are important component of hard turning as it directly influences the heat generation, accuracies and tool wear. The Eq (1) of continuous turning and Eq (2) of interrupted turning indicates that the feed in both the cases have the positive effect on $F_{c}$. This is consistent with the findings from the cutting force model proposed by $\frac{18}{18}$ during continuous machining of hardened AISI H11 tool steel ${ }^{5}$ and during interrupted hard turning of AISI 51200. Cutting speed has a negative effect on $\mathrm{F}_{c}$ in continuous turning whereas it has no effect during inter- rupted turning under the domain of the cutting speed range.

The plausible reason could be that as the cutting speed increases the shear angle increases, resulting in shorter plane/area reduction in chip thickness and hence the machining force decreases. The other reason could be as the tool is continuously in touch with work material in continuous machining, increase in the cutting speed increases the friction between the tool and the workpiece, hence more heat is generated in the cutting zone and excessive melting of the material, therefore the thermal softening of the blocked material in front of the tool tip takes place decreasing the cutting forces. Cutting speed range considered in this experimental study could not influence the cutting force due to less heat generation in interrupted turning. Higher the feed, higher will be the resistance from the workpiece to the cutting tool in feed direction and higher will be the friction. As the feedrate increases the chip load on the tool increases, hence the energy generated at primary and secondary zone increases, thereby increasing the thrust forces causing more vibration and heat generation. The interaction of the tool type and feed in case of interrupted turning is significant because the tool material properties and the tool edge preparation has more important role to play in interrupted turning than continuous turning.

\subsection{Thrust Forces}

The prediction equations for thrust forces in coded variables along with the R-squared statistics are as follows:

$$
\begin{aligned}
& \mathrm{F}_{\text {P-CONT }}=211.80-2.11 \mathrm{~A}+0.33 \mathrm{~B}-4.18 \mathrm{C} \quad(1)-12.59 \mathrm{C} \quad(2)- \\
& 16.75 \mathrm{BC}(1)-9.09 \mathrm{BC}(2)-26.44 \mathrm{~A}^{2}-16.22 \mathrm{~B}^{2} \\
& \left(\mathrm{R}^{2}=0.7958 ; \quad \text { Adjusted } \mathrm{R}^{2}=0.7050 ; \quad\right. \text { Predicted } \\
& \left.\mathrm{R}^{2}=0.5546\right) \\
& \mathrm{F}_{\text {P-INTER }}=179.66-10.13 \mathrm{~A}+3.11 \mathrm{~B}-33.79 \mathrm{C}(1)-4.71 \mathrm{C}(2)- \\
& 14.13 \mathrm{BC}(1)-11.55 \mathrm{BC}(2)-77.20 \mathrm{~B}^{\wedge} 2 \\
& \left(\mathrm{R}^{2}=0.8746 ; \text { Adjusted } \mathrm{R}^{2}=0.8248 ; \text { Predicted } \mathrm{R}^{2}=\right. \\
& 0.7328)
\end{aligned}
$$


The thrust force models Eq $(3 \& 4)$ indicate that the model is negatively influenced by cutting speed in continuous turning and postively influenced in interrupted turning. The interrupted turning does not have a thermal softening effect near the shear zone during engagement of the tool and hence significant increase in thrust force as established by previous studies. These high cutting forces induce transient vibrations, which bring fluctuation in cutting speed and depth of cut. This relative change in cutting speed induces more tool wear due to beating effect. As observed, the coefficient estimate of feed in interrupted turning is higher, suggesting greater role of feed and appropriate edge preparation required in interrupted turning.

From the results, it is seen that both the cutting forces increase if the feed rate is higher owing to increased tool wear and because of the increased contact area of the tool flank wear land and the workpiece. Possibly increase of feed rate induces a larger volume of the cut material in a same unit of time, besides establishing a dynamic effect on the cutting forces. Additionally, it is observed that the interaction effect of feed and the CBN type provides secondary contribution to the thrust force.

\subsection{Cutting Temperatures}

The prediction equations for cutting temperatures in coded varaiables along with the R-squared statistics are as follows:

$\mathrm{T}_{\mathrm{CONT}}=+543.64+19.89 \mathrm{~A}+1.06 \mathrm{~B}+4.78 \mathrm{C}(1)+2.78 \mathrm{C}(2)-$

8.06AC (1)-2.22AC (2)-45.33 $\mathrm{A}^{2}-11.36 \mathrm{~B}^{2}$

$\left(\mathrm{R}^{2}=0.8821\right.$; Adjusted $\mathrm{R}^{2}=0.8297$; Predicted $\mathrm{R}^{2}=$ 0.7282 )

$\mathrm{T}_{\text {INTER }}=+434.76+16.50 \mathrm{~A}+11.75 \mathrm{~B}+9.67 \mathrm{C} \quad(1)+12.89 \mathrm{C}$

(2) $-11.19 \mathrm{~A}^{2}$

$\left(\mathrm{R}^{2}=0.8042\right.$; Adjusted $\mathrm{R}^{2}=0.7576$; Predicted $\mathrm{R}^{2}=$

0.6763 )

The cutting temperature model Eq (5\&6) indicate that the cutting speed have positive influence on cutting temperature both in continuous and interrupted cutting i.e as the cutting speed increases the cutting temperature increases due to higher friction. The heat generated by the workpiece during chip formation in the deformation zone is transferred into the workpiece, chip and tool. The surface area of the interrupted workpiece is more than that of the continuous surface and hence more heat loss to the surrouding, therefore lower temperature are recorded in interrupted turning as compared to continuous turning. The effect of cutting speed and friction cannot be speculated here in interrupted turning due to discontinuous heating and cooling cycle due to nature of cut i.e "on" and "off" cut period resulting in temporal active temperature gradient. The temperature of the cutting tool rises during the cut period due to generated shear andfrictional heat and decreases during the non-cut period due to the forced convection of the air. On rotation of the workpiece, the air-flows through the channel formed due to interrupted surfaces, which keeps both the workpiece and tool cold. In $\frac{19}{}$ explained that the rise in temperature in continuous turning is due to increase in cutting speed and increase in feed rate has no influence on the cutting temperature. The effect of feed is more prominent in interrupted turning because of the beating effect.

The other observation that can be made from the model is the interaction of cutting speed with CBN tool type, in continuous turning, which have a strong influence on cutting temperature unlike in interrupted turning. This shows that the thermal property of tool material plays a significant role in continuous turning, as similar to the edge preparation in interrupted turning.

\subsection{Surface Roughness}

The prediction equations for surface roughness in coded varaiables along with the R-squared statistics are as follows:

$$
\begin{aligned}
& \mathrm{R}_{\mathrm{a}-\mathrm{CONT}}=1.02+0.027 \mathrm{~A}+0.69 \mathrm{~B}+-0.069 \mathrm{C}(1)-0.091 \mathrm{C}(2)- \\
& 0.12 \mathrm{BC}(1)-0.12 \mathrm{BC}(2)-0.078 \mathrm{~A}^{2}-0.29 \mathrm{~B}^{2} \\
& \left(\mathrm{R}^{2}=0.9817 ; \text { Adjusted } \mathrm{R}^{2}=0.9735 ; \text { Predicted } \mathrm{R}^{2}=\right. \\
& 0.9579)
\end{aligned}
$$


$\mathrm{R}_{\mathrm{a}-\mathrm{INTER}}=0.84+0.37 \mathrm{~B}-0.25 \mathrm{C}(1)+0.035 \mathrm{C}(2)+0.12 \mathrm{BC}$ $(1)+0.24 \mathrm{BC}(2)+0.52 \mathrm{~B}^{2}$

$\left(\mathrm{R}^{2}=0.8550\right.$; Adjusted $\mathrm{R}^{2}=0.8115$; Predicted $\mathrm{R}^{2}=$ $0.7383)$

The surface roughness model Eq (7\&8) indicates the relative linear effect of feed in both continuous and interrupted turning. Since the material is hard and hence less plastic, the surface finishes are better according to. Surface roughness value increases with increase in feed rate and decreases with increase in cutting speed have also been underlined in a study by. However, the machining theory by ${ }^{20}$, which says that the feed and nose radius, plays a significant role for surface roughness $\left\{R a \cong \frac{f 2}{32 \times \text { nose radius }}\right\}$ when the tool edge is sharp. Since the cutting edge is not sharp and have specific geometric features (edge preparation) as shown in Table 4, some other factor influences the surface roughness. In continuous turning, the surface roughness is good at higher cutting speed and is poor at lower cutting speed. Here the accumulated material ahead of the prepared cutting edge suppress the effect of feed and tool point. At higher speed, the volume of the accumulated material is high, there by the effect gets more supressed, consequently, the surface roughness becomes low. As observed, the surface roughness obtained in interrupted turning are slightly better than continuous turning. The plausible reason could be that there are several free surfaces due to the slots unlike a single free surface in a solid cylindrical bar, therefore, the lateral flow of the material are not constrained thereby decreasing the peak to valley height of the machined surface profile. Also better surface finish was produced with worn tools with larger nose radius as established. This could also be the possible reason as interrupted cutting leads to wear of tool nose.

But with increased feed rate, the thrust force increase, leading to vibrations and more heat generation thereby resulting in higher surface roughness value in both the cases.

\section{SEM AND EDAX Analysis of Worn Tools}

\subsection{Tool Wear}

Researchers have suggested that the CBN tool wear is a complex phenomenon and hard turning involves more than one wear mechanism occuring at a time. Further, it is very difficult to pin point the relative importance of a particular wear mechanism involved for a specific wear mode. The cutting edge is subjected to a combination of high stresses, high temperatures, chemical reactions, mechanical shocks and different tool/work material, which causes the tool to wear due to one or more mechanisms at a time. due to one or more mechanisms at a time. After the hard machining was done on continuous and interrupted surfaces the worn tools were examined using SEM and EDAX to affirm the wear modes and mechanism.

Figure 2(A)-Figure 2(D) represents the worn tools with various tool wear occurred during machining. All the machining were done at $0.133 \mathrm{~mm} / \mathrm{rev}$ feed and a constant depth of $0.15 \mathrm{~mm}$. The above feeds and depth of cut were selected with an objective to achieve better surface quality, minimum tool wear and match the equivalent material removal rate of the grinding process. Two different cutting speeds used were $60 \mathrm{~m} / \mathrm{min}$ and $102 \mathrm{~m} / \mathrm{min}$ representing low and moderate cutting speed range. The machining tests were terminated until a fresh insert failed due to chipping/fracture or surface roughness produced was more than $3 \mu \mathrm{m}$. Figure $2(\mathrm{~A})$ and $(\mathrm{C})$ represents the worn tool at $60 \mathrm{~m} / \mathrm{min}$ and $102 \mathrm{~m} / \mathrm{min}$ respectively in continuous turning. In both the cases the nose cutting edges degraded after each subsequent pass and poor surface finsh were observed. As seen the chipping and the crater wear increased with increased interaction time between tool and work material. The tool experienced larger crater wear after 15 minutes of machining time, broke off completely due to highly and plastic deformation. Both the inserts were roughly used for machining good surfaces for a less than 15 minutes before the tool failed. Figure 


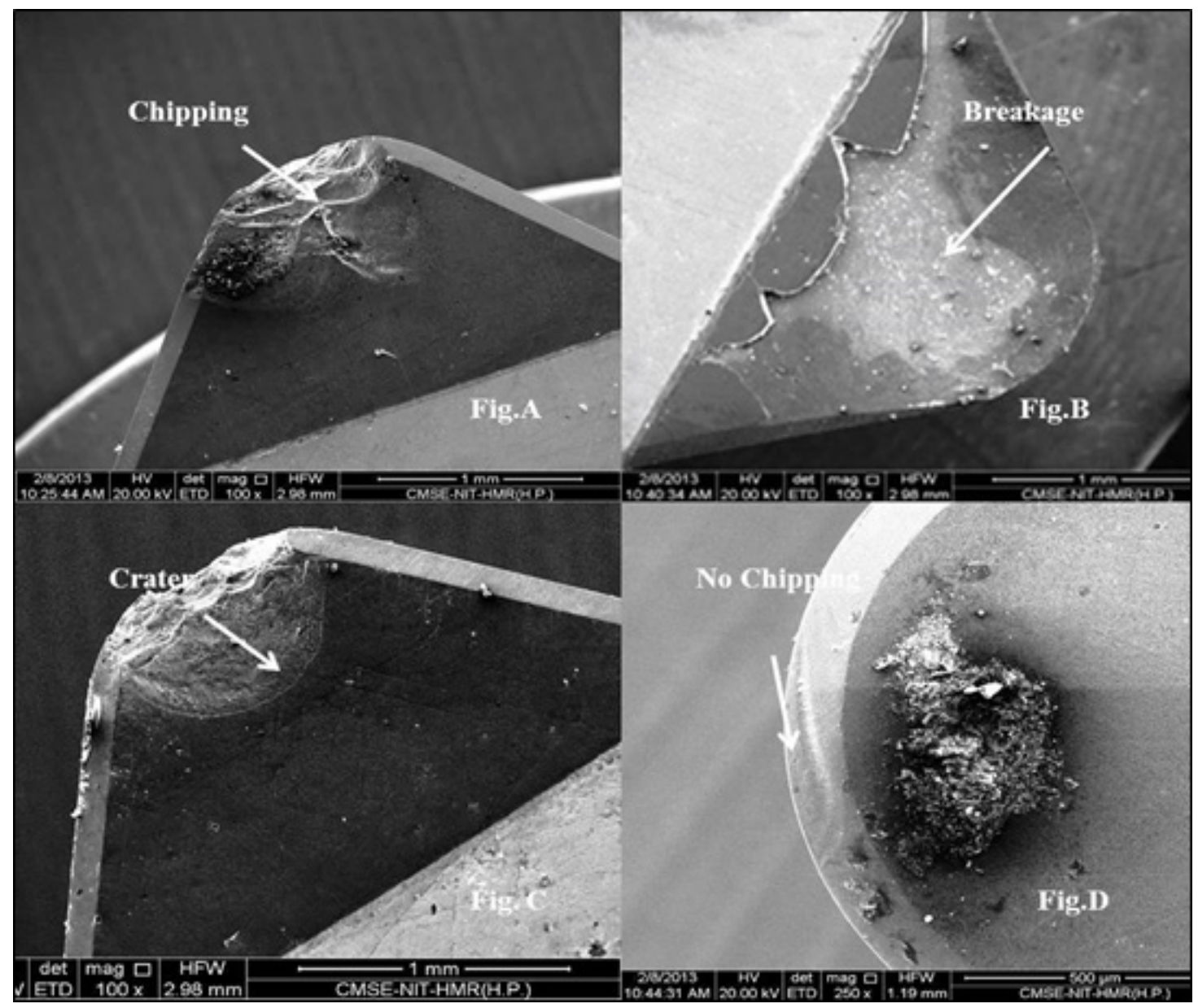

Figure 2. Various tool wear in continuous and interrupted machining.

2 (B) and (D) represents the worn tools at $60 \mathrm{~m} / \mathrm{min}$ and $102 \mathrm{~m} / \mathrm{min}$ respectively in interrupted turning. At $60 \mathrm{~m} /$ min poor surface roughness were obtained immediately due to the affected cutting edge, which failed because of the mechanical hammering by the interrupted surfaces suggesting the stress conditions at the cutting edge were uncomplimentary. Figure 2(D) shows no chipping of cutting edge and the tool at relatively good conditions and the surface roughness observed were in the range of 0.48 $1.15 \mu \mathrm{m}$.

The tool toughness is sufficient to absorb the shock load and prevent chipping of the edges. The tool wear study shows the CBN-L tools at $102 \mathrm{~m} / \mathrm{min}$ is resilience to chipping and fracture.

\subsection{Tool Wear Mechanisms}

The tool wear mostly depends on the tool grades, workpiece-geometry, hardness, material compositions and cutting conditions. It can be concluded that generally abrasion, adhesion, diffusion and tribo-chemical wear of CBN tools are prominent tool wear mechanisms. However, the individual effect of each mechanism in hard continuous and interrupted turning depends on material compositions, cutting condition and tool geometry as suggested by. Since the machining experiments were done on the AISI D6 tool steel with a $2.1 \%$ carbon, obviously hard carbide particles/clusters are present in martensitic structures depending upon the steel composition. The hardness of the carbides (cementite) of Cr, Mo, W and V 


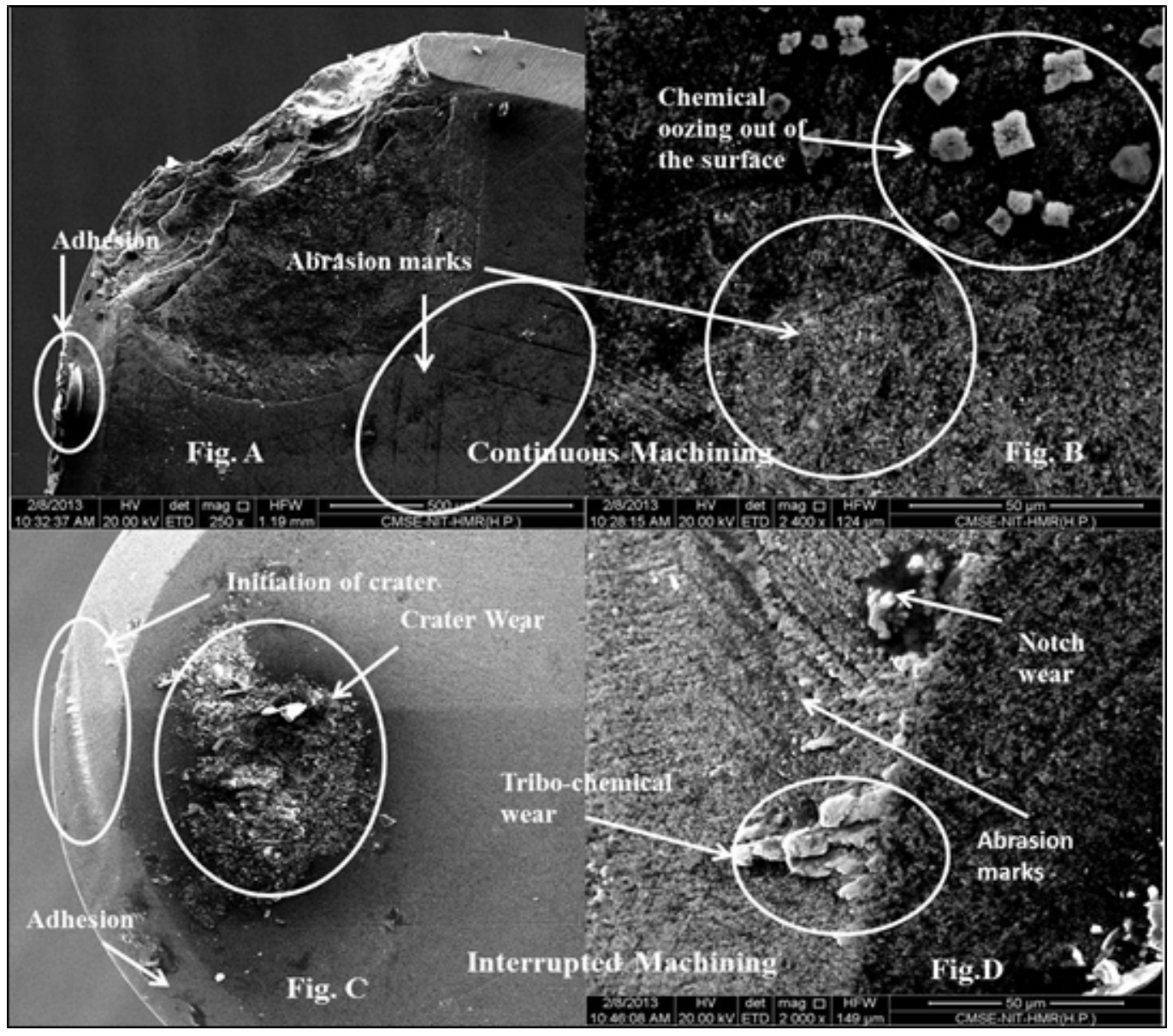

Figure 3. Various Tool wear mechanisms in continuous and interrupted machining.

mostly in tool steel is around $12 \mathrm{KN} / \mathrm{mm}^{2}$. But the CBN grains are much harder than any hard carbide particles with $45 \mathrm{KN} / \mathrm{mm}^{2}$. Abrasion occurs due to the free CBN particles/chip/hard carbides all removed from the surface of the tool and work material by stick-slip get sandwiched between the chip-tool rake face/tool-work flank face and thereby crafting a medium, subject to three body abrasion, which results in the mechanical abrasive wear. The abrasion marks are clearly visible on the worn tools shown in Figure 3(A)-(D) in continuous turning. The same reasons can be attributed to interrupt hard turning. Due to low percentage of CBN content in CBN-L, the wear resistance of these tool decreases. At the same time the cutting temperature remains low in interrupted turning, due to whirling of air through the slots, it is highly unlikely that the ceramic binder loses its strength and let off the CBN grains to fall, rather the abrasive effect of hard carbide particles of AISI D6 in the martensitic structure, rubbing the tool surface could be the possible reason for the abrasive marks during interrupt turning. Adhesion occurs when machining of hardened steel involves high temperature and stresses on the cutting edge, due to which the workpiece material or chip melts and adheres to the tool's non-contact surface. This was not prominently found in both the cases because of low temperatures at low cutting speed. The other reason adhesion was not predominantly visible during interrupted turning because of high frequency impacts on the tool edges and low temperatures. Due to the interruptions the rise and fall of temperature (alternating heating and cooling cycles) leads to successive 


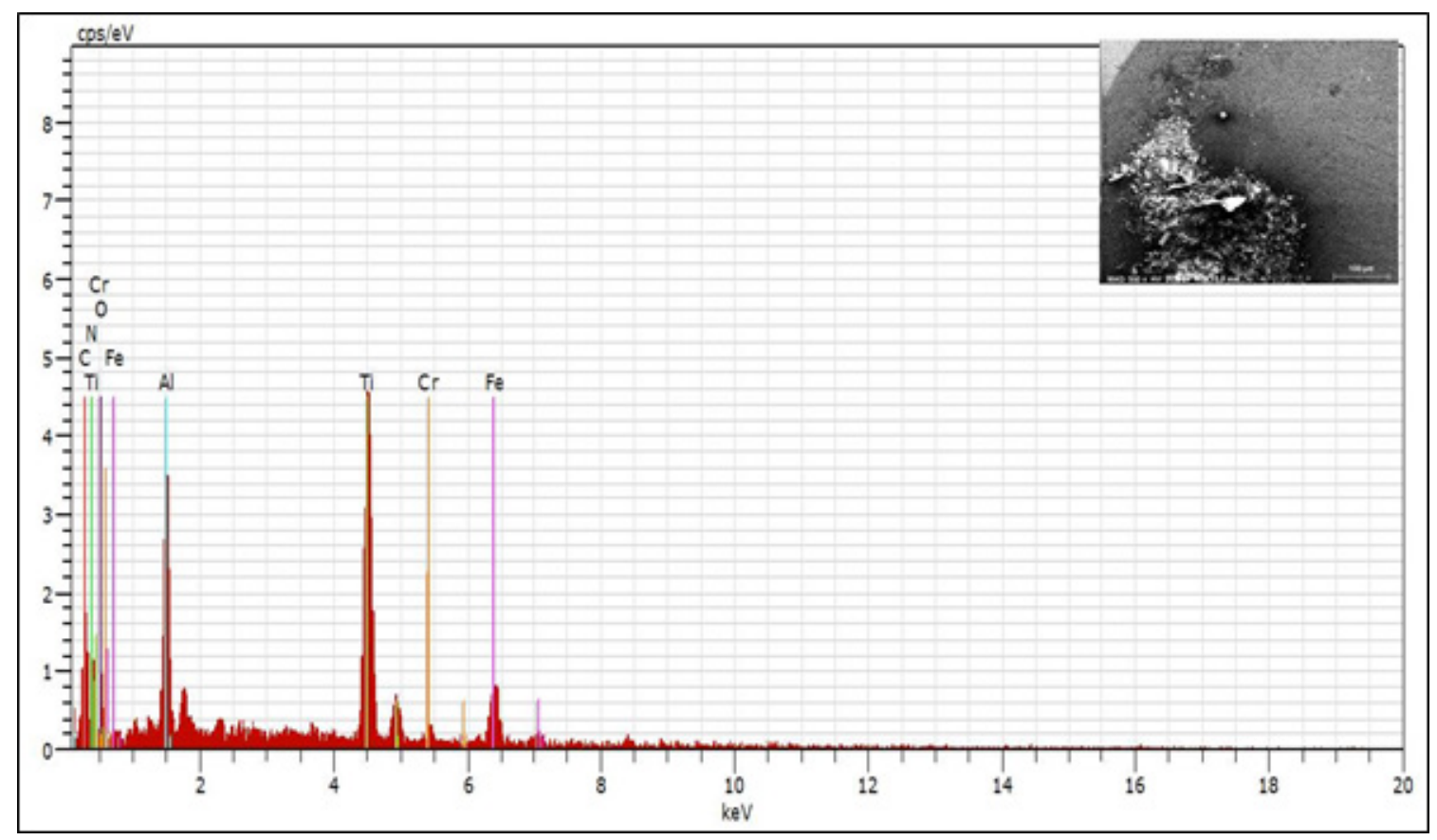

Figure 4. EDAX of worn tools of continuous machining.

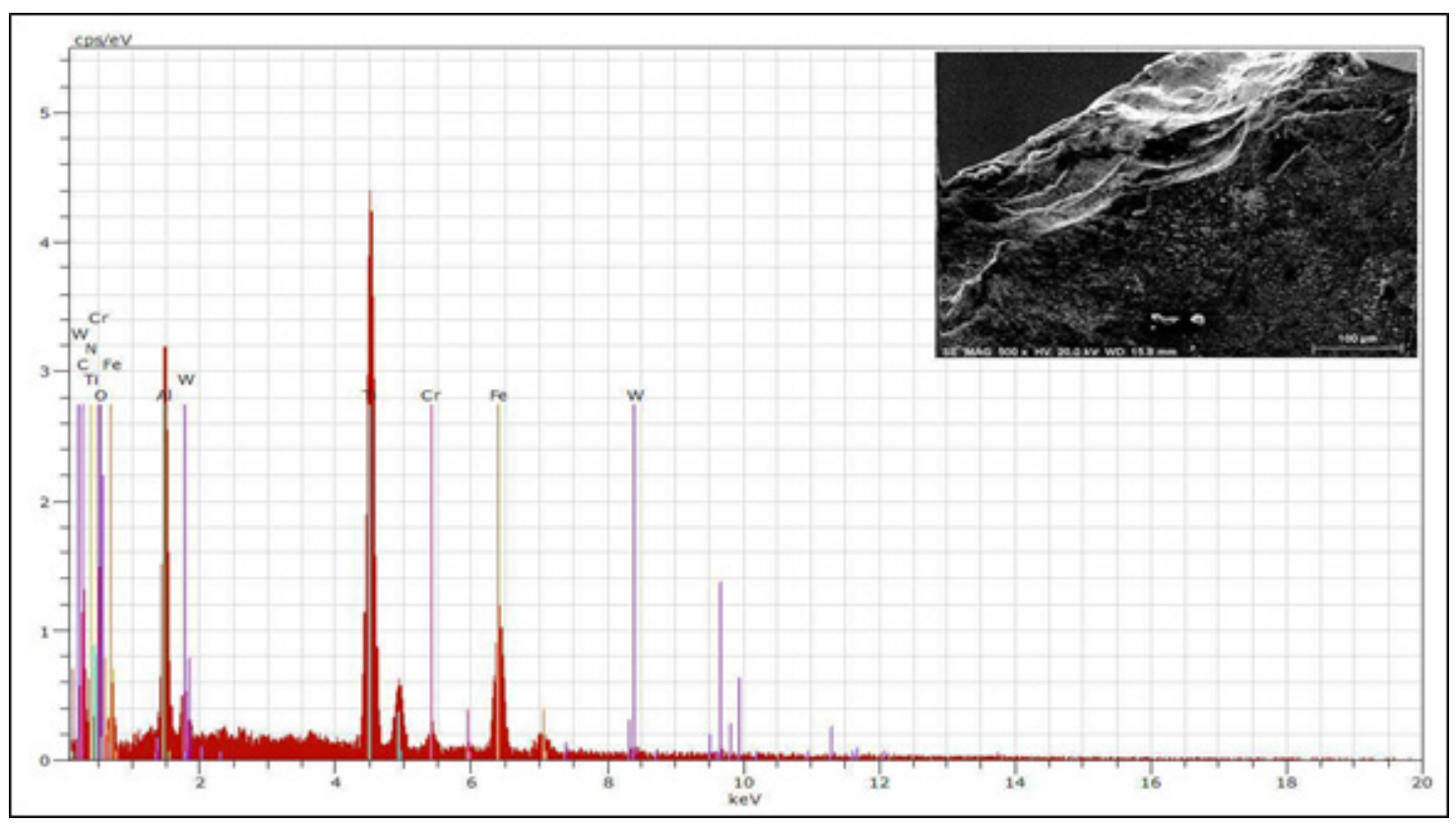

Figure 5. EDAX of worn tools of interrupted machining.

expansion and contraction of the material at the specific area and induces transient vibrations, thus making it difficult for adhered material to stick. High temperatures stimulate diffusion and chemical dissolution mechanism to take place between the work and tool material. 
It can be speculated that since the CBN-L tools with ceramic binder have low thermal conductivity compared to high content CBN tools with the metallic binder, the low CBN tools are chemically stable with some of the metallic element of the chip. For example during this experimental study, the EDAX analysis shows elements like vanadium, tungsten, cobalt of work-piece material was seen in continuous machining as shown in Figure 4 but not seen diffusing during interrupted machining as shown in Figure 5. Though the chemical stability of the low $\mathrm{CBN}$ tool is high, few elements like $\mathrm{Cr}, \mathrm{Al}, \mathrm{Fe}$ of the work piece material were found from the layer and $\mathrm{Ti}$ and $\mathrm{N}$ obviously from the binder material of the tool. Presence of $\mathrm{O}$ and $\mathrm{N}$ from the atmosphere indicates the possibility of oxidation wear mechanism.

The SEM images Figure 3(B) and (D) were found to contain some unidentified chemical compound, which are squeezed out in molten state indicating the formation of some new compounds due to the chemical interaction of the tool and work-piece material with the surrounding. These reactionary products of carbides, nitrides, borides and oxides of constituent metallic elements of both tool and work-piece material suggesting $\mathrm{CBN}$ tool wear involves chemical wear Specific compound formation cannot be assessed from EDAX results but the presence of specific elements with their weight percentage can be identified. It is also possible that a significant amount of silicon dioxide may be present because of the presence of silicon in hardened AISI D6 steel. In this case it will have a significant effect on the tool wear process and the silicon dioxide is a tribo-chemical product.

\section{Conclusions}

The following conclusion can be drawn from the present study:

- The thrust force is the dominant force as compared to the main cutting force. Both the forces increase with feed, a combination of low feed and high cutting speed is desirable for minimizing the cutting forces in both interrupted and continuous cutting.
- The thrust forces in interrupted cutting were of higher magnitude than that in continuous cutting. The interaction of feed and tool material have a secondary effect on thrust forces.

- The cutting temperature model indicates that the cutting speeds have positive influence and feed have minimum influence in continuous cutting whereas feed have a prominent influence on interrupt cutting.

- Feed strongly influences the surface roughness model for both continuous and interrupted cutting; the surface roughness is good at higher cutting speed and is poor at lower cutting speed. The surface roughness obtained in interrupted cutting was much better than interrupted cutting.

- The prediction models presented fairly good result with reasonable error percentage.

- Chipping and fracture are the dominant wear modes in hard turning using low CBN content tool. Abrasion, diffusion and tribo-chemical wear are the different wear mechanisms observed during hard turning of AISI D6 steel.

- CBN-L tools are sufficiently tough to perform well at $102 \mathrm{~m} / \mathrm{min}$ in interrupted cutting based on surface roughness but produce poor surface finish in continuous cutting at all speeds.

\section{References}

1. Bartarya G, Choudhary S.K. State of the art hard turning, International Journal of Machine Tool Manufacturing. 2012; 53(1):1-14. https://doi.org/10.1016/j.ijmachtools.2011.08.019.

2. Huang Y, Liang SY. Modeling of cutting forces under hard turning conditions considering tool wear effect, Trans, ASME Journal of Manufacturing Science Engineering. 2005; 127(2):262-70. https://doi.org/10.1115/1.1852571.

3. Yan H, Hua J, Shivpuri R. Numerical simulations of finish hard turning for AISI H13 die steel, Science and Technology of Advanced Material. 2005; 6(5):540-47. https://doi. org/10.1016/j.stam.2005.04.002.

4. Huang Y, Liang SY. Cutting forces modeling considering the effect of tool thermal property application to CBN hard turning, International Journal of Machine 
Tool Manufacturing. 2003; 43(3):307-15. https://doi. org/10.1016/S0890-6955(02)00185-2.

5. Ozel T. Modeling of hard part machining: effect of insert edge preparation in CBN cutting tools, Journal of Material Processing Technology. 2003; 141(2):284-93. https://doi. org/10.1016/S0924-0136(03)00278-4.

6. Lima JG, Avila RF, Abrao AM, Faustino M, Davim JP. Hard turning: AISI 4340 high strength low alloy steel and AISI D2 cold work tool steel, Journal of Material Processing Technology. 2005; 169(3):388-95. https://doi.org/10.1016/j. jmatprotec.2005.04.082.

7. Arsecularatne JA, Zhang LC, Montross C, Mathew P. On machining of hardened AISI D2 steel with PCBN tools, Journal of Material Processing Technology. 2006; 171(2):244-52. https://doi.org/10.1016/j.jmatprotec.2005.06.079.

8. Chen W. Cutting forces and surface finish when machining medium hardness steel using CBN tools, International Journal of Machine Tool Manufacturing. 2000; 40(3):45566. https://doi.org/10.1016/S0890-6955(99)00011-5.

9. Ko TJ, Kim HS. Surface integrity and machinability in intermittent hard turning, International Journal of Advanced Manufacturing and Technology. 2001; 18(3):168-75. https://doi.org/10.1007/s001700170072.

10. Chou YK. Hard turning of M50 steel with different microstructures in continuous and intermittent cutting, Wear. 2003; 255(7-12):1388-94. https://doi.org/10.1016/S00431648(03)00102-9.

11. Chou YK, Evans CJ. Cubic boron nitride wears in interrupted hard cutting, Wear. 1999; 255-29(1):234-45. https:// doi.org/10.1016/S0043-1648(99)00012-5.

12. Diniz AE, Oliveira AJ. Hard turning of interrupted surfaces using CBN tools, Journal of Material Processing Technology. 2008; 195(1-3):275-81. https://doi.org/10.1016/j.jmatprotec.2007.05.022.

13. Nayak M, Sehgal R. Effect of cutting conditions and CBN grades on machining of AISI D6 steel during hard turning, Arabian Journal of Science and Engineering. 2015;
40(4):1151-64. https://doi.org/10.1007/s13369-015-15780 .

14. Mechanical Characterization and Machinability Behavior of Annealed AISI D6 Cold Working Steel. Date accessed: 15/05/2015. https://www.hindawi.com/journals/ ijms/2015/196178/, https://doi.org/10.1155/2015/196178.

15. Design and Analysis of Experiment. Date accessed: 2009. https://support.sas.com/content/dam/SAS/support/en/ books/design-and-analysis-of-experiments-by-douglasmontgomery/66584_excerpt.pdf.

16. Lazoglu I, Buyukhatipoglu K, Kratz H, Flocke F. Forces and temperatures in hard turning, Machining Science and Technology. 2006; 10(2):157-79. https://doi. org/10.1080/10910340600713554.

17. Lalwani DI, Mehta NK, Jain PK. Experimental Investigations of cutting parameters influence on cutting forces and surface roughness in finish hard turning of MDN250 steel, Journal of Material Processing Technology. 2008; 206(1-3):167-79. https://doi.org/10.1016/j.jmatprotec.2007.12.018.

18. Fnides B, Yallese MA, Mabrouki T, Rigal JF. Application of response surface methodology for determining cutting forces model in turning hardened AISI H11 hot work tool steel, Sadhana Indian Academy of Science. 2011; 36(1):10923. https://doi.org/10.1007/s12046-011-0007-7.

19. Yallese MA, Chaoui K, Zeghib N, Boulanour L, Rigal JF. Hard machining of hardened bearing steel using CBN tool, Journal of Material Processing Technology. 2009; 209(2):1092-104. https://doi.org/10.1016/j.jmatprotec.2008.03.014.

20. Metal Cutting Principal. Date accessed: 2005. https://www. academia.edu/31367766/Metal_Cutting_Principles_2nd_ Edition_-_By_Milton_C._Shaw_.

21. Ota M, Kukino S, Uesaka S, Fukaya T. Development of SUMIBORON PCBN tools for machining of sintered powder metal alloys and cast iron, SEI Technical Review. 2005; 59:61-72. 